\title{
DICTADURA, MEMORIA Y LITERATURA: LAS VARIACIONES SIMBÓLICAS DEL TRAUMA
}

\author{
DITADURA, MEMÓRIA E LITERATURA: \\ AS VARIAÇÕES SIMBÓLICAS DO TRAUMA
}

\author{
Cecilia María Teresa López Badano ${ }^{1}$ \\ Linet Cums Yumar ${ }^{2}$
}

\begin{abstract}
RESUMEN: En la investigación literaria contemporánea, el corpus integrado por representaciones simbólicas de la memoria histórica traumática ocupa un lugar preponderante en países donde hemos padecido dictaduras o poderes autoritarios. En el Cono Sur, las exploraciones literarias de la memoria cuentan ya con cierta tradición y con variaciones narrativas que abarcan desde una épica heroica acerca de las víctimas, a visiones que la anulan o fragmentan paradójicamente el relato memorístico; en otros países, como los centroamericanos o Bolivia, las revisiones son más recientes y presentan diferencias e, incluso, controversias internas en el relato respecto de la visión individual y colectiva de la memoria histórica. En consecuencia con lo dicho, se revisarán algunas representaciones simbólico-literarias de la memoria producidas contemporáneamente en diversas regiones latinoamericanas y con diferentes concepciones estéticas. La intención principal del presente trabajo es explorar las formas en que la literatura, de un modo más accesible que las Ciencias Sociales -y tan reflexivo como el de los planteos de éstas- simboliza actualmente el trauma histórico-político y se enfrenta a las problemáticas generadas por éste.
\end{abstract}

Palabras clave: Literatura; memoria; trauma; dictaduras latinoamericanas.

RESUMO: Na pesquisa literária contemporânea, o corpus integrado por representações simbólicas da memória histórica traumática ocupa um lugar preponderante nos países que sofreram ditaduras ou poderes autoritários. No Cone Sul, as explorações literárias da memória contam já com alguma tradição e com variações narrativas que abarcam desde uma épica heroica a respeito das vítimas, até visões que a anulam ou subdividem paradoxalmente o relato memorizado; em outros países, como os da América Central ou Bolívia, as revisões são mais recentes e apresentam diferenças e, inclusive, controvérsias internas no relato a respeito da visão individual e coletiva da memória histórica. De acordo com o que foi dito, serão revistas algumas representações simbólico-literárias da memória produzidas contemporaneamente em diversas regiões latino-americanas e com diferentes concepções estéticas. A intenção principal do presente trabalho é explorar as formas em que a literatura, de um modo mais acessível que as Ciências Sociais -e tão reflexivo como é o de suas abordagens - simboliza atualmente o trauma histórico-político e enfrenta as problemáticas geradas por ele.

Palavras-chave: Literatura; memória; trauma; ditaduras latino-americanas.

\footnotetext{
1 Doctora en Romance Languages por la University of Oregon-USA. Estágio posdoctoral en el Instituto Iberoamericano de Berlín. Docente Investigadora de Tiempo Completo. Facultad de Lenguas y Letras Universidad Autónoma de Querétaro - UAQ, México.

2 Licenciada en Letras por la Universidad de La Habana-Cuba. Maestría en Enseñanza de la Literatura. Investigadora independiente. Conferencia sobre educación literaria, Universidad Autónoma de Querétaro México. Postulante en el Doctorado en Literatura Latinoamericana UNAM.
} 
La memoria es la forma más sofisticada de síntesis. (Ariel Urquiza, Ya pueden encender las luces, 2019, p. 126)

Cuando, durante fines de los 80 hasta principios de este siglo, la conciencia de las masacres latinoamericanas pergeñadas por las dictaduras militares conosureñas de los 70 comienza a volcarse en la letra, aparece un tipo de ficción anamnética que, a través de la poetización y de cierto lirismo, intenta reconstruir la memoria desde un "mesianismo débil" en el sentido planteado por Walter Benjamin en las Tesis de Filosofía de la Historia-; a esta concepción responden algunos textos de Tomás Eloy Martínez (El cantor de tango, Purgatorio), varios de Nona Fernández (Mapocho, Fuenzalida, el cuento "1 de noviembre") y uno en particular de Roberto Bolaño, Amuleto -entre otros de él que exploran desde diversos ángulos, el tema de la memoria: Nocturno en Chile, por ejemplo, e incluso y aunque sea subliminalmente, el tema de la venganza o la "revancha", como Estrella distante-; menciono Amuleto en particular porque es quizás ése entre todos los citados en referencia a la anamnesis, el que señala el punto de inflexión hacia el desencanto testimonial de las corrientes contemporáneas latinoamericanas. ${ }^{3}$

Las nuevas producciones al respecto, desilusionadas y controvertidas, alejadas del "espíritu épico", irrumpen con su temática inquietante ya durante el presente siglo y van ganando su terreno paulatinamente, conforme el tiempo avanza; marcan como constante actual que la concepción mesiánica, salvífica, "rescatista" - de algún modo "fetichizada" positivamente en la ya mencionada Amuleto- está en retroceso frente a esta nueva corriente avasalladora de otro tipo de ficción, unas veces fragmentaria en el horror; otras, desencantada de las posibilidades reconstructivas del recuerdo y el testimonio, pobre de certezas sobre la subjetividad de los personajes, que son personalidades devastadas por la violencia de estado, o bien, relatos con planteos internos que apuntan hacia controversias entre protagonistas acerca del propio concepto de "memoria", incluso, a veces, relacionando inalienablemente su contenido a otro término excluido de la mayoría de las primeras narraciones y problematizado en algunas de las recientes, es decir: "venganza".

A pesar de su desencanto con el poder "sanador" y mesiánico de la memoria patente en relatos anteriores, la mayoría de estas narrativas contemporáneas sobre el trauma histórico impuesto por las diversas dictaduras latinoamericanas, apunta, de modos variados aunque convergentes, a que el lector pueda vislumbrar el horror de lo siniestro que siempre permea sus discursos.

Estas narrativas son, en buena medida, “antiauráticas” y alejadas de la estética literaria tradicional, ya que su preocupación principal no está centrada en ese plano, e incluyen, a veces, otras apoyaturas formales más allá de la palabra (por ejemplo, fotos distantes del presente de la

\footnotetext{
${ }^{3}$ El tema de Amuleto como punto de inflexión es tratado con mayor extensión en un artículo actualmente en prensa, pero en una explicación breve de lo afirmado, diríamos que el sentido de la titulación no se descubre hasta el final de la novela. ¿Qué queda del canto libertario enarbolado con convicción por los jóvenes que se despeñan hacia el abismo? El recuerdo convertido en amuleto ¿y qué es un amuleto sino un fetiche al que le damos el poder de sostenernos? En eso se convierte el canto entonces: en un fetiche para la autoconvicción ante lo que se desmorona irreparablemente.
} 
historia narrada, dibujos garabateados por una niña, elementos que refuerzan un sentido de "realismo fragmentario", como sucede en Lengua madre, de la argentina María Teresa Andruetto); en algunos de esos relatos se suele constituir un figurado realismo que se autoniega como tal en sus incertidumbres, en su imposibilidad de reconstruir la subjetividad y el sufrimiento de las víctimas a través de visiones contrastivas (entrevistas pseudo testimoniales cuyos interrogados se contradicen unos a otros en sus declaraciones -como en La mujer en cuestión, de la misma Andruetto-); aparecen narradores distantes, en abismo, que no recuerdan los hechos porque no se hallaban en un momento de conciencia racional (como en Estrellas muertas, de Álvaro Bisama, donde la narradora principal -narrada, a su vez, por otra persona que no tuvo contacto directo con el hechos, pero sí con ella- estaba bajo el adormecedor efecto de su adicción al jarabe para la tos en el momento en que sucedían los hechos relatados-); en otras narraciones, la fragmentariedad discursiva y la distancia cultural -como en Insensatez, de Horacio Castellanos Moya- son factores que niegan, en forma subliminal o explícita, la posibilidad de una auténtica memoria colectiva y/o de reconstrucción de la personalidad dañada.

Aunque en la mayoría de estas ¿ficciones? se explora un borde conjetural contradictorio que anula toda afirmación conclusiva, no por ello se vela la consternación del espanto, ya que si bien no hay certezas narrativas, la propia contradicción aparente, lo paradojal, encierra para sus lectores uno de esos momentos de claridad, de esos destellos inesperados que alumbran y se filtran desde la cámara oscura de la Historia, una de esas epifanías que se apagan rápidamente pero permanecen en algún lugar de la memoria, fijadas, con la fuerza de lo que no se deja atrapar en su totalidad, pero puede vislumbrarse en la misma incertidumbre. Como señalaba Walter Benjamin en las Tesis 5 y 6 :

La verdadera imagen del pasado transcurre rápidamente [...] sólo puede retenérselo en cuanto imagen que relampaguea, para nunca más ser vista, en el instante de su cognoscibilidad. «La verdad no se nos escapará»; esta frase, que procede de Gottfried Keller, designa el lugar preciso en que el materialismo histórico atraviesa la imagen del pasado que amenaza desaparecer con cada presente que no se reconozca mentado en ella. (La buena nueva, que el historiador, anhelante, aporta al pasado viene de una boca que quizás en el mismo instante de abrirse hable al vacío). Articular históricamente lo pasado no significa conocerlo «tal y como verdaderamente ha sido». Significa adueñarse de un recuerdo tal y como relumbra en el instante de un peligro. Al materialismo histórico le incumbe fijar una imagen del pasado tal y como se le presenta de improviso al sujeto histórico en el instante del peligro.

El peligro que se intuye, lo siniestro que se filtra, son también reveladores para el lector; por ejemplo, el ensayista y crítico del arte Georges Didi-Huberman, en su libro Imágenes pese a todo. Memoria visual del Holocausto (a partir de Hannah Arendt), defiende el valor testimonial de cuatro fotografías tomadas desde el interior de una cámara de gas por un Sonderkommando; las imágenes a las que se refiere son borrosas, están, desde una perspectiva fotográfica exigente, "mal encuadradas", remiten con locuacidad a lo urgente de sus circunstancias de producción. Esas fotografías, como él mismo señala, han permanecido desatendidas por los historiadores "convencionales", ya sea por desconfianza acerca de una supuesta parcialidad de la imagen o por simple prevención próxima a la ceguera; cuando se han usado con valor testimonial, se las ha manipulado, ampliándolas o recortándolas, reenfocándolas, en busca, como se suele fundamentar, de mayor objetividad, que se traduzca -siempre desde esa misma perspectiva- en 
mayor claridad de la información. El instante de "verdad" concentrado en el gesto nervioso aunque firme de quien se sublevó para capturar de algún modo aquella dimensión oculta y, en consecuencia, atrapar el destello congelado en el registro fotográfico "imperfecto", no ha sido suficientemente valorado.

Uno de los argumentos de Huberman para rebatir este enfoque tradicional, más allá del supuesto de que todo testimonio, oral, escrito o visual, es incompleto en relación con la Historia, es decir, que nadie está en condiciones de relatar lo traumático sin fracturas, se funda en el presupuesto concerniente a que, por fuera de lo que dejan ver las imágenes fotográficas, se debe reconocer las condiciones en que fueron capturadas, su fenomenología, y en particular, atender al sujeto que obturó la cámara, quien se arriesgó no tanto a morir -que era lo ya esperable- sino a las torturas impuestas por los nazis para castigar cualquier acto de sublevación. Ese gesto de lo que podríamos llamar "obturar en la desesperación" es el que captan estas nuevas narrativas: de Benjamin recuperan al menos eso -la conciencia iluminadora del centelleo-, aunque ya no apuesten siquiera al mesianismo débil: visibilizan en un relámpago, el mismo de la cámara del Sonderkommando.

¿Cómo desechar o recortar el testimonio de un sujeto que, pese a todo, se rebela y decide enviar al futuro, en condiciones extremas, un instante de verdad? Esas circunstancias que enmarcan las fotografías, en literatura, equivaldrían al tono, al modo peculiar en que un narrador logra capturar la historia que relata; las fotografías mencionadas, tanto como las novelas de nuestro corpus, muestran, a diferencia de la simple información, lo que la Historia por lo general oculta: el lado personal, instantáneo, cotidiano, en que un sujeto vive y resiste el horror. Desde la psicología ya se ha alegado largamente sobre la imposibilidad de simbolizar el trauma, pero cabe preguntarse qué sucede con el relato literario que, en estas narraciones contemporáneas, transgrede el impedimento e intenta superarlo, tratando de representar el sufrimiento.

El libro de Huberman, construido en diálogo con los testimonios de los sobrevivientes de los campos de concentración, refuta la pereza de quienes se conforman con aquello de lo indecible, de la imposibilidad de relatar o pensar los hechos atroces de la Historia porque como se suele alegar- "no estuvimos allî". Mucho antes que él, Arendt alertaba sobre el peligro de esta lógica cómplice respecto del plan macabro de los nazis, quienes desde los primeros momentos, tuvieron por norma borrar las pruebas de lo que sucedía -como también hicieron varias dictaduras latinoamericanas, siguiendo su ejemplo, y en algunos casos, incluso, con secretos e "iniciáticos" pactos de sangre- y se regodeaban en la suposición de que nadie ajeno al círculo ejecutor, podría imaginar lo que allí pasaba.

A partir de ese saber establecido por la imposición del horror, podemos afirmar que toda autocracia aspira a hacer invisible a sus oponentes y, con ello, sepultar los mecanismos de esta desaparición, es decir, apuesta al ocultamiento, mismo que la literatura violará sistemáticamente, aunque más no sea, desde un espacio intersticial y contradictorio, donde la conjetura, quizás más que ver, nos permite vislumbrar, y ese vislumbre, en el oscuro túnel de lo desconocido, materializa lo siniestro.

Así, la vacilación del habla - "antiaurática”-, la contradicción, la dificultad del testimonio frente al horror padecido, se asumen, en la literatura, como problema -estético- y como punto de partida de los relatos, porque allí donde se instala "la banalidad del mal" para dejar a los individuos helados y mudos, en ese límite incandescente entre entender y no hacerlo, la única salida es el acto de imaginar, aunque más no sea, en la contradicción y en la incertidumbre, para resistir a la imposición del olvido. Sin embargo ¿cómo conciliar la - 
supuesta- indecibilidad del trauma con la exigencia de "decibilidad" que impone la literatura? Para relacionarlo con las fotografías mencionadas ¿cómo pensar en el sujeto que las produjo sin manipular las imágenes, sin lesionar su "fuera de foco" que las hace creíbles en la desesperación?

Un punto que se puede encontrar como central entre ambas visiones -la psicológica y la literaria- se nos presentó como objeto de reflexión a través de un seminario con la doctora Francoise Davoine, excelente especialista en temas de trauma, locura y memoria, además de refinada literata: cuando algunos de los asistentes le planteamos ciertos casos de violencia extrema que se han vivido en México y cuáles son las posibilidades de sanar para quienes los padecieron, ella respondió que era necesaria la palabra de los testigos, es decir "colocar testimonios allí donde hay sufrimiento". Quizás -hipotetizamos- esté allí el eje conflictivo central en la simbolización que muestran estas nuevas narrativas, pues uno de sus puntos cruciales es, precisamente, el quiebre y la incertidumbre del discurso testimonial. A continuación, exploraremos algunas de ellas.

Las dos novelas mencionadas más arriba tienen en común tanto el tipo de personaje central -víctimas femeninas de la represión dictatorial, con las consecuencias traumáticas que esto conlleva, para consigo mismas y para con los demás- como la "estetización" a partir de cierto "montaje" de datos aportados por personajes externos -narradores obligados por diversas circunstancias a reunir voces y pareceres contradictorios, pero no testigos directos-; la intimidad de las protagonistas -casi incognoscible y abismalmente enigmática en su carácter devastado por la violencia de Estado- se diseña entonces a partir de esas miradas alejadas y externas que colocan en abismo ${ }^{4}$ a esas mujeres; así los rasgos introspectivos se vuelven presuntivos y/o inaccesibles, desrealizándolas a la vez que las configuran a través de un ambiguo diseño que decantan diversas voces empañadas por la contradicción, la inconsciencia, la subjetividad.

No se trata sólo de que sea difícil o imposible recordar, sino más bien, de que son recuerdos ambiguos y confusos a los que el relato, a fuerza de retazos, pugna por darles significado. En la espesura de lo que va aflorando en la narración se entrecruzan los sentidos elusivos de varias historias con los más explícitos de la tiránica Historia padecida socialmente, porque se da cuenta de al menos treinta años en ambas historias nacionales (la argentina y la chilena).

Este tipo de construcción, necesariamente, fractura las certezas del epos; como señala Pampa Arán, el efecto de real "desborda el marco de una reconstrucción histórica y del pacto de lectura del realismo tradicional para mostrar, más que un saber sobre lo real, su problematización desde el presente" (2005, p. 24). Podría agregarse entonces que se apunta a releer ese pasado histórico a través de las subjetividades devastadas contemporáneas, lo cual significa, obviamente, hablar de las consecuentes ruinas, bastante irreparables, del momento actual -simultáneo al relato-, porque ambas historias son también las de la quiebra definitiva de una forma de vida, donde tanto la decadencia como el aislamiento de las protagonistas representan, además, el fracaso de una manera de concebir la sociedad y las relaciones entre sus individuos: el derrumbe, ante el avasallamiento brutal de las dictaduras, de los lazos solidarios construidos, de la utopía -sociopolítica- como "horizonte regulador ético del presente" $(\mathrm{APEL})^{5}$.

\footnotetext{
${ }^{4}$ Nos referimos a esta figura literaria con el mismo sentido que aporta la Dra. Helena Beristaín: "Relato interno", "duplicación interior", "narración en primero y segundo grado". Quizá -concluye- "estructura abismada” sea, en castellano, una denominación precisa" (1993-94, p. 37).

${ }^{5}$ El filósofo trata reiteradamente el tema; al respecto, puede verse Scilovetto, Gonzalo (2017) Ética e historia: una
} 
Un dato llamativo respecto de estas narrativas contemporáneas del trauma y la memoria también es que algunos autores que habían escrito las primeras narraciones conmemorativas en su país, actualmente, a casi una década y media de aquello, se enrolan en la nueva corriente, y si bien mantienen el pathos, desisten del epos, que se fragmenta en recuerdos, en canciones, en retazos rescatados. Es el caso de la chilena Nona Fernández, quien mereció en México el premio Sor Juana Inés de la Cruz 2017 por su última "novela", si es que puede llamarse así a un texto que, en forma espiralada y recurrente, integra investigación personal con estructura de crónica, recuerdos, y datos autobiográficos de los que parte para reconstruir la historia de uno de los militares devenidos verdugos: "el hombre que torturaba" -Andrés Antonio Valenzuela Morales, miembro del servicio secreto de la Fuerza Aérea- quien, por declarar ante una revista opositora al régimen militar de Pinochet en qué consistía su "trabajo", fue puesto en un programa de protección a testigos y salió exiliado a Francia; su historia conducirá a las de algunas de sus víctimas.

La autora, como el fotógrafo de nuestro inicio, registra también el proceso de narrar un acto de resistencia: en este caso, la sublevación se despliega como un relato "otro", necesariamente "desenfocado" (porque no hay datos verificables, concretos, a partir de la desaparición forzada, sino imaginación) frente a los modos informativos de la política chilena. Si la información "llana" reduce, clasifica, organiza, ya que parte de su propio carácter "económico" es el acto mismo de simplificar ofreciendo al lector una historia efectiva por manipulada -reenfocada-, el acto de narrar a contrapelo (distanciándose de los vencedores) como sugería Walter Benjamin también en las Tesis (7) -agregaríamos nosotros: desde el pathos (incluso, desde el pathos personal, biográfico o la em-pathía, que autoriza la imaginación del pathos adjudicado a las víctimas) más que desde el epos- enuncia su oposición política, su sublevación.

La rebelión se simboliza a través de un doble movimiento: el de la temática elegida -la señalada, que parte, fragmentariamente, del testimonio clave formulado por el represor e intenta reconstruir la constelación de hechos derivados de aquella enunciación, considerando, además, la relación personal de la narradora y otros personajes con esa historia, donde, consecuentemente, el elemento autobiográfico, conlleva intermitentes cruces con la historia política nacional- y, sobrevolando aquello, el del impulso imaginativo que ofrece un manejo de la historia y del lenguaje exento de respuestas rápidas, clausuradas.

La narración se sostiene sobre la forma de una pregunta siempre abierta o sobre la estructura tambaleante de una investigación tortuosa. Se narra lo que no se comprende, se acude a la escritura como un modo subjetivo de averiguar y descifrar las zonas oscuras de la realidad, también, de socializarlas. Resta mucho que decir en torno a la historia reciente de Chile y esta novela pretende abrir un espacio para las voces anónimas, los testigos del horror que han sido silenciados por una política violenta primero, y después por otra, que quiere llamarse, amablemente, de reconciliación.

Hasta aquí hay una constante que atraviesa una posible conversación sobre La dimensión desconocida, ésta tiene que ver con la relación tensa existente entre narración e información. ¿Por qué empezábamos recordando la fotografía desenfocada, tomada en un campo de concentración? Había, en el gesto del Sonderkommando que aprieta el obturador, una

mirada desde la ética discursiva / Ethics and history: A look from the discursive ethics / Ética e história: uma visão de ética do discurso. Accesible en:

https://www.researchgate.net/publication/318085387_Etica_e_historia_una_mirada_desde_la_etica_discursiva_E thics_and_history_A_look_from_the_discursive_ethics_Etica_e_historia_uma_visao_de_etica_do_discurso. 
formulación muy clara de resistencia frente a la consigna o la información estandarizada del lenguaje de la historia oficial, de los políticos y los medios, el mismo que se dispara en la tensión del relato entre información e imaginación.

Así, la autora parte del nombre de aquel inquietante programa norteamericano traducido al español como "la dimensión desconocida", cuyo título en inglés era The twilight zone, lo que lo ligaba también con la hora crepuscular y la cercanía de la noche. En el texto se relaciona ese espacio ignoto con el de la desaparición forzada, entonces es necesario considerar ciertas connotaciones derivadas de la titulación, como ser, que cada emisión televisiva se valía de la ciencia ficción para sortear la censura de canales y patrocinadores a lo que implicara, al menos potencialmente, críticas de la realidad social del país, por consiguiente, el recurso a ese ámbito ficcional específico era utilizado por guionistas y productores como metáfora explicativa de situaciones sociales candentes, metáfora que surtió efecto, porque logró su cometido de difusión; Nona atiende a ese hecho, pero descartando la ciencia y utilizando la ficción para develar lo oculto, ya sin temor a la censura.

Otro de los factores relacionados con el título es que la desaparición forzada (denominada usando como transitivo un verbo que era intransitivo, es decir "desaparecer-loslas", lo que revela, en su distorsiva innovación gramatical, la violencia del régimen) impuesta al "enemigo" -un ciudadano opositor, que podía o no ser militante político- constituía una de las estrategias principales del terrorismo de Estado: para corroborarlo, basta tener en cuenta una frase tristemente célebre del dictador argentino Jorge Rafael Videla -quien compartía, primordial pero no exclusivamente, con sus pares chileno y uruguayo, la cómplice inserción ideológica y de acción en el Plan Cóndor ${ }^{6}$ - frase formulada ante el interrogante sobre las personas "ausentadas", cuyo paradero los familiares, sus abogados y algunos periodistas buscaban saber: "Es una incógnita: un desaparecido. No tiene entidad. No está, ni muerto ni vivo. Está desaparecido"?

La desaparición forzada es, precisamente, en la novela, el acceso a "la dimensión desconocida", es decir, el ingreso a una espiral vertiginosa cuyo punto central siempre se ignora: aquel limbo que iniciaba cuando se perdía contacto con un ser querido secuestrado violentamente y arrojado al baúl o al piso trasero de un Ford Falcon; desde entonces, su existencia comenzaría a diluirse, pasando a ser un NN, sobre todo, si era asesinado luego de la tortura y su cadáver, enterrado clandestinamente.

En consecuencia con lo dicho, también la denominación NN se relaciona con "la dimensión desconocida", ya que si bien en latín esa sigla correspondía a "nomen nescio" (nombre desconocido), los nazis la resignificaron usándola como "Nacht und Nebel" (noche y

\footnotetext{
6 "Operación Cóndor" o "Plan Cóndor" es la denominación del programa coordinado de acciones y mutuo apoyo entre las cúpulas de los regímenes dictatoriales del Cono Sur y con los Estados Unidos; se señala como su ideólogo principal a Henry Kissinger, por entonces jefe del Departamento de Estado. Fue concretado entre las décadas de los $70^{\circ}$ y $80^{\prime}$ y su fin era la imposición de un plan económico neoliberal a partir del desmantelamiento del Estado como articulador y garante de la vida pública y el desarrollo socio-económico, sumado a un endeudamiento externo de crecimiento exponencial. Para ello, la mayor parte de los dictadores militares latinoamericanos y/o sus adláteres fueron entrenados en la Escuela de las Américas (SOA), institución que, durante los años álgidos de la Guerra Fría, afianzó la lealtad de las Fuerzas Armadas latinoamericanas a la política exterior estadounidense.

${ }^{7}$ Esta situación es captada magistralmente por dos escritores previos, digamos "de mesianismo débil": Cristina Peri Rossi tomando en cuenta el punto de vista de quien padece esa suspensión en su propia vida, en la novela La nave de los locos, de 1984 (capítulo IX, "El viaje. La fábrica de cemento”) y Tomás Eloy Martínez, considerando el punto de vista de quien busca y espera a un "desaparecido", en su última novela: Purgatorio, del 2008.
} 
niebla), palabras tomadas de la tercera escena de la ópera El oro del Rin, de Richard Wagner ${ }^{8}$, lo cual confirma el afán propio de varios jerarcas de sublimar el crimen con un arte que ha destituido la búsqueda de redención religiosa, purificándose idealmente a través de éste. Su sigla simboliza el ¿lugar? donde "se perdían" las víctimas de la desaparición forzada; la orden de privarlas de su libertad disponiendo de sus vidas sin dejar rastros visibles y contraviniendo el derecho que la Convención de Ginebra garantizaba a los prisioneros de guerra, se conoció, bajo el régimen hitleriano, como "Decreto NN"

La novela se propone recuperar, desde la imaginación, el último tramo en la vida privada o pública, conocida, de una serie de desaparecidos, es decir, tanto seguir sus últimos pasos, deseos y aliento "de este lado", como imaginar y describir el tiempo-espacio de violencia ocupado cuando estuvieron en "la dimensión desconocida", por lo tanto, el nombre de aquel lejano programa televisivo, se convierte, en la textura literaria, también en un cronotopo de la desaparición forzada.

Las historias narradas tienen un detalle en común: en la desaparición de sus protagonistas intervino la misma persona, es decir, el torturador arrepentido y exiliado, quien en el relato funge como umbral de acceso a "la dimensión desconocida", ya que a través de su testimonio se reconstruyen tentativamente las biografías de las víctimas, en general, militantes de izquierda.

Casi no hay en el texto caracterizaciones heroicas, sino vida cotidiana truncada cuando el terror de Estado la invade, y en cuanto al torturador, además de la vida cotidiana "laboral" que se vuelve cada día más siniestra, y entra progresivamente en colisión con su mundo familiar y doméstico, detonando pesadillas, la incógnita literaria que flota, sin respuesta, como una interrogación retórica fundante - ¿el punto que origina la espiral, quizás?- es qué lleva a una persona a convertirse en alguien de accionar monstruoso.

Se hurga entonces en esa zona insondable, íntima, de extravío moral, de vacío ético que es también una dimensión desconocida, pero en este caso, subjetiva, impenetrable- donde la naturaleza humana deviene bestial; por una parte, entonces, lo inquietante es que esa "dimensión desconocida" psicológica, privada, se vuelve, en la novela, mucho más próxima de lo que uno podría imaginar, porque como la autora misma ha afirmado "la realidad doméstica tiene siempre una grieta que lleva a un lugar fantasmagórico", entonces se pregunta reiteradamente, anclando el texto al presente “qqué habría hecho yo?", ya que, si bien "no somos culpables, sí somos responsables" (del silencio, de haber mirado hacia otro lado, del miedo); por otra parte, lo consolador es que se produzca un punto de inflexión, aunque tal vez no de

\footnotetext{
${ }^{8}$ (Alberich se coloca el yelmo mágico)

El yelmo se ajusta a la cabeza: ¿ocurrirá el hechizo?

(En voz muy baja)

Noche y niebla. ¡Ya no hay nadie!

(Su figura desaparece y en su lugar surge

una columna de niebla.)

¿Puedes verme, hermano?

(Mime mira sorprendido a su alrededor)

¿Dónde estás? ¡No puedo verte!. (Huhle s/f)

${ }^{9}$ Nombre eufemístico y sintético de las "Directivas para la persecución de las infracciones cometidas contra el Reich o las Fuerzas de Ocupación en los Territorios Ocupados" (Richtlinien für die Verfolgung von Straftaten gegen das Reich oder die Besatzungsmacht in den besetzten Gebieten). Fue declarado como un acto de crimen de guerra por el Tribunal Internacional Militar de Nüremberg, que reconstruyó sus 40 páginas secretas; su principal firmante, el mariscal Wilhem Keitel, fue condenado, así como juzgados otros jerarcas nazis por cargos derivados de su participación en el plan implicado y ejecutado particularmente entre 1942 y 1944 acorde con el Decreto NN.
} 
arrepentimiento: el hecho de que un atisbo de humanidad orille al verdugo a testimoniar aun sabiendo que su vida corre peligro, quizás acorralado por el insomnio o la pesadilla, pero sólo después de que lo irreparable se haya instalado definitivamente para otros.

En todo caso, la carta imaginaria al "hombre que torturaba" -misma que también forma parte de la novela- queda sin respuesta y, en la exhibición del documental guionado y referido por la autora, proyectado en la sala más pequeña de un multicine de centro comercial, el único público presente son ella y su madre iqué ha pasado entonces con la memoria? Evidentemente, pasada la efervescencia comercial -y sensacionalista- del tema en la inmediata postdictadura, esa sala de cine minúscula y vacía, también opera como metáfora: la memoria -y su recuperación- es un film que se exhibe sin público, un film que sólo miramos cuatro humanistas benjaminianos, vengadores mesiánicos del olvido persiguiendo utopías: el resto del público prefiere Avengers II, y eso también es desencanto, el desencanto de una generación que creció a la sombra sangrienta de la dictadura, sin poder relacionar sus observaciones fragmentarias -y esto inhibía la creación de una conciencia que ligara lo privado individual a lo público social-; una generación obligada a mirar hacia otro lado por padres que, aterrados, los hacían cerrar puertas y ventanas cuando el terror de Estado prostituía la vida cotidiana con el tableteo de sus armas, esa generación que ahora, sin culpa, pero herida y sangrando sin poder cicatrizar, tampoco halla redención, ni siquiera en la escritura, pero puede, al menos, imaginarla y fantasear la que no tuvieron sus personajes y con ello, nos permite vislumbrar el horror.

Por falta de espacio, nos quedará pendiente la exploración de otros textos que reafirman la idea de cierto quiebre en el discurso testimonial, de esa fragmentación que permite atisbar lo siniestro desde la estética de la imaginación narrativa: uno, paradigmático, es Insensatez, de Horacio Castellanos Moya, que narra la masacre guatemalteca implicada en el genocidio indígena a manos militares, cuyo momento álgido fue entre 1982-83, bajo el gobierno de facto de Efraín Ríos Mont, cuando, con la excusa del "enemigo interno subversivo", fuerzas contrainsurgentes promovieron el exterminio de más de 400 comunidades mayas asentadas en la "Franja Transversal del Norte", con la finalidad real de ocupar sus tierras, ubicadas en la cuenca de exploración petrolera extranjera en el país. También la reciente y controvertida En el cuerpo, una voz (2018), del boliviano Maximiliano Barrientos, que discute las nociones de memoria, resentimiento, venganza y locura frente al general asesino que condujo las masacres supremacistas de inicios del presente siglo, y podríamos seguir enumerando, pero de lo analizado, rescataríamos algunos términos a modo de sintética conclusión: por un lado, hablaríamos, como ya se señaló, de pathos versus epos, pues en estos relatos en general alejados voluntariamente del esteticismo y la experimentación formal, predomina la densidad de la catástrofe psicológica de al menos, dos generaciones por sobre la épica estética enaltecedora, "heroicisante" de las narrativas anteriores; por otro, no es arbitrario que en los textos analizados surjan dos términos para definir lo formal: estructura en abismo - estructura en espiral, donde el abismo nos conduce a la caída sin fondo ni red, y el espiral busca constantemente el punto de origen de esa estructura mareante y regresiva sobre sí misma, sin encontrarlo y, por lo tanto, sin poder extirparlo.

Se reconstruyen realidades omitidas, se crean espacios imaginarios -pero verdaderosque encadenan sucesos, recuerdos, estableciendo relaciones de causalidad con el objetivo de dar al material histórico una forma menos rudimentaria. La manera dubitativa, fragmentaria y/o contradictoria de enfrentar los hechos constituye el nexo que atraviesa y da entidad finalmente al manejo del material histórico con el que trabajan los autores; los narradores se desplazan imaginariamente a cada zona velada por la Historia. 
Ricardo Piglia comentó en su discurso de recepción del premio José Donoso en Chile, y a propósito de los desaparecidos de la dictadura militar en Argentina, que "las narraciones muchas veces captan esos lugares donde un testigo recuerda un momento de una historia que en otras dimensiones ha sido borrada" (2014, 246), sin embargo, como apuntó en su diario, siempre hay un testigo -como pedía también Francoise Davoine- y "la verdad de los débiles logra a veces hacerse oír" $(2017,16)$. Digamos, entonces también con él, que "la narración alude y desplaza, nunca dice de manera directa cuál es el sentido y ahí se define su forma" $(2014,245)$; la dilación del sentido que describe como marca de toda verdadera narración, se instala en varias de estas novelas al inscribir, a la manera habitual y no por ello menos estremecedora de los testigos del horror, la paralización del habla, la contradicción, la paradoja. Los relatos reconocen su insuficiencia frente a los sucesos brutales que buscan escrutar, pero insisten en hablar, a pesar de todas las dificultades.

\section{Bibliografía}

ANDRUETTO, M.T. Lengua madre. Buenos Aires: Literatura Random House, 2015.

ANDRUETTO, M.T. La mujer en cuestión. Buenos Aires: Literatura Random House, 2017.

APEL, K.-O. ¿Es la ética de la comunidad ideal de comunicación una utopía? Acerca de la relación entre ética, utopía y crítica de la utopía. En: Estudios Éticos. México: Distribuciones Fontamara, pp. 177-221, 2004.

ARÁN, P. Biografías no autorizadas: la identidad del héroe. En: ROMANO SUED, S.; ARÁN, P. (ed.). Los '90. Otras indagaciones. Córdoba: Epoké, 2005.

BARRIENTOS, M. En el cuerpo, una voz. Buenos Aires: Eterna Cadencia, 2018.

BENJAMIN, W. Tesis de filosofía de la historia. Revolta global/Formacio (1950) <http://www.anticapitalistas.org/IMG/pdf/Benjamin-TesisDeFilosofiaDeLaHistoria.pdf $\geq$ [consultado el 13/09/2019].

BERISTAIN, H. Enclaves, encastres, traslapes, espejos, dilataciones (la seducción de los abismos), Acta Poética. México: UNAM, pp.14-15, 1993-94.

BISAMA, Á. Estrellas muertas. Santiago: Aguilar Chilena-Alfaguara, 2010.

BOLAÑO, R. Amuleto. Barcelona: Anagrama, 1999.

BOLAÑO, R. Nocturno en Chile. Barcelona: Anagrama, 2000.

CASTELLANOS MOYA, H. Insensatez. México: Tusquets, 2004.

DIDI HUBERMAN, G. Imágenes pese a todo. Memoria visual del Holocausto. Trad. Mariana Miracle. Barcelona: Paidós, 2004.

FERNÁNDEZ, N. La dimensión desconocida. México: Literatura Random House, 2017.

FERNÁNDEZ, N. Mapocho. Santiago: Planeta, 2002.

FERNÁNDEZ, N. Primero de noviembre. El Cielo. Santiago: Cuarto Propio, 2001.

HUHLE, R. Noche y niebla. Mito y significado. Traducción de Albert Roves. Desapariciones forzadas de niños en Europa y Latinoamérica. Del convenio de la ONU a las búsquedas a través de ADN. 
En: CASADO, María y LOPÉZ ORTEGA, Juan José (coord.). Barcelona: Universitat de Barcelona, s/f, pp. 252-277. Disponible desde internet en:

<http://www.archivomuseodelamemoria.cl/uploads/2/7/278925/00000544000002000001.pd $\mathrm{f} \geq$ Consultado el 19/6/2019.

MARTÍNEZ, T. E. El cantor de tango. Buenos Aires: Planeta, 2005.

MARTíNEZ, T. E. Purgatorio. Buenos Aires: Alfaguara, 2008.

PERI ROSSI, C. El viaje. IX. La fábrica de cemento. La nave de los locos. (1984). Barcelona: Seix Barral (Biblioteca de Bolsillo), 1989.

PIGLIA, R. Los diarios de Emilio Renzi. Un día en la vida. Barcelona, Anagrama, 2017.

PIGLIA, R. Modos de narrar, Antología personal. Buenos Aires: FCE, 2014.

Recebido em: 13/05/2020

Aceito em: 13/07/2020 